\title{
¿Ciencia versus moral? Revisión histórico-científica sobre el síndrome del zika congénito y la reivindicación del aborto
}

\author{
(Science versus moral? \\ Historical-scientific review \\ of congenital zika syndrome \\ and the advocacy of abortion)
}

\section{HÉLIO TADEU LUCIANO DE OLIVEIRA}

Universidad de Navarra, Pamplona

hluciano@unav.es

ORCID: 0000-0003-4561-6231

\begin{abstract}
Resumen. En 2015 empieza una epidemia causada por el virus del zika en Brasil, siendo luego asociada a problemas teratógenos congénitos. A partir de la sospecha de esta relación, surgen, en dos vertientes, artículos defendiendo el aborto: (1) presentándolo como uno de los tratamientos para las mujeres embarazadas; (2) utilizando la crisis sanitaria y la confusión de la opinión pública como una estrategia para despenalizar el aborto. Las dos vías son injustas al exigir que los recursos ya escasos fuesen destinados al aborto y no a la prevención, tratamiento y cuidados necesarios a los afectados. Se concluye que los datos científicos, en si mismos, son acordes a la inmoralidad del aborto, siendo justamente la falta de rigor científico y/o las cuestiones ideológicas los que lo promueven.
\end{abstract}

Palabras-clave: Virus del zika; Brasil; problemas congénitos; aborto; justicia.

ScientiaetFides 9(1)/2021, 309-327 
Abstract. In 2015, an epidemic caused by the zika virus begins in Brazil and is later associated with congenital teratogenic problems. From the suspicion of this relationship, articles defending abortion arise in two ways: (1) presented as one of the treatments for pregnant women; (2) using the health crisis and the confusion of public opinion as a strategy to decriminalize abortion in countries where it is prohibited. Both approaches are unfair in that they demand that already scarce resources be used for abortion and not for the prevention, treatment and care of those affected. It is concluded that the scientific data are in keeping with the immorality of abortion, with the lack of scientific rigor and/or ideological issues being precisely what promotes it.

Keywords: Zika virus; Brazil; congenital problems; abortion; justice.

\section{Introducción}

El virus del zika (ZIKV) fue descubierto en 1947, en Uganda, siendo prácticamente inofensivo a los humanos durante las primeras décadas desde su descubrimiento (Dick, Kitchen y Haddow 1952; Dick 1952; Simpson 1964). Entre el 2007 y el 2014, se evidencia un cambio en la patogenicidad del virus, que provoca algunas epidemias a gran escala en algunas islas del Pacífico (Hayes 2009) y pasa también a ser asociado al Síndrome de Guillain-Barré (GBS) (Kucharski, et al. 2016).

A mediados de 2015, en Brasil, se detecta una epidemia causada por el ZIKV, siendo que pocos meses más tarde, todavía en el 2015, por primera vez, se asocia esta enfermedad a problemas teratógenos congénitos (Zanluca, et al. 2015; Campos, Bandeira y Sardi 2015). La importancia de esta asociación se hace manifiesta cuando la Organización Mundial de la Salud (OMS) declara ser la infección por ZIKV una emergencia de salud pública de importancia internacional (ESPII) ${ }^{1}$, y cuando, en abril de 2016, los Centers for Disease Control and Prevention (CDC) americanos y la OMS confirman la teratogenicidad de la enfermedad. ${ }^{2,3}$

1 World Health Organization. 'WHO Director-General summarizes the outcome of the Emergency Committee regarding clusters of microcephaly and Guillain-Barré syndrome'. 2016: en línea: http://www.who.int/mediacentre/news/statements/2016/emergency-committee-zika-microcephaly/en/. Fecha de consulta: 11 de febrero de 2020.

2 Centers for disease control and prevention. 'CDC concludes Zika causes microcephaly and other birth defects'. 2016: en línea: https://www.cdc.gov/media/releases/2016/s0413-zika-microcephaly.html. Fecha de consulta: 11 de febrero de 2020.

3 World Health Organization. 'Informe sobre la situación, 14 de abril de 2016. Virus del Zika, microcefalia y síndrome de Guillain-Barré’. 2016: en línea: http://apps.who.int/iris/ 
Dentro de este amplio contexto de salud pública, este trabajo presenta una revisión bibliográfica para entender un punto específico: cómo, desde distintas perspectivas, se ha presentado el ZIKV -y los problemas congénitos derivados- en relación a la reivindicación del aborto ${ }^{4}$. Es verdad que dentro de la amplia bibliografía científica sobre el ZIKV -más de ocho mil artículos indexados en Pubmed - son pocos los que tratan de modo directo o indirecto de esta temática; sin embargo, en estos pocos, es relevante ver la disociación que existe entre los datos científicos y la promoción del aborto.

A partir de esta revisión de la literatura médica será posible considerar si, dentro del contexto presentado, la inmoralidad del aborto se trataría solo de un absoluto moral ${ }^{5}$ o si dicho absoluto correspondería a los hechos científicos.

\section{Argumentos que proponen el aborto como tratamiento adecuado a los problemas derivados de la infección por ZIKV}

Muchas de las publicaciones científicas que surgen a partir de la eclosión de la epidemia del ZIKV en Brasil tratan del aborto no en plan reivindicativo, sino presentándolo -dentro de la comprensión que tienen los autores de estos artículos- como una opción válida de tratamiento.

Dentro de este primer grupo surgen muchos artículos que insisten en la cuestión diagnóstica como modo de ofrecer la posibilidad a que la mujer decida por el término del embarazo en tiempo oportuno, según la legislación

bitstream/10665/205568/1/zikasitrep_14Apr2016_spa.pdf?ua=1. Fecha de consulta: 11 de febrero de 2020.

4 Distinta de otras definiciones, como la utilizada por la Organización Mundial de la Salud, utilizamos aquí la definición de aborto dada por la encíclica Evangelium Vitae: [...] la eliminación deliberada y directa, como quiera que se realice, de un ser humano en la fase inicial de su existencia, que va de la concepción al nacimiento (EV, 58).

5 La norma moral de la prohibición del aborto puede ser expresada desde distintas perspectivas filosóficas y teológicas. Aquí asumimos la determinada por la encíclica Evangelium Vitae: Por tanto, con la autoridad conferida por Cristo a Pedro y a sus Sucesores, en comunión con los Obispos de la Iglesia católica, confirmo que la eliminación directa y voluntaria de un ser humano inocente es siempre gravemente inmoral (EV, 57). 
de cada país. No intentan la aprobación y ni siquiera la discusión en sí del aborto, sino que lo consideran simplemente como uno de los "tratamientos" válidos. En este sentido, podemos ver, por ejemplo, la revisión sistemática realizada por Hajra et al.:

Las mujeres embarazadas que tienen hallazgos ecográficos fetales sugestivos de síndrome del zika congénito o resultados positivos o no concluyentes de la prueba de laboratorio materna para la infección por ZIKV pueden ser candidatos para la amniocentesis fetal. Esta información puede afectar la decisión sobre la interrupción o no del embarazo [...] (Hajra, et al. 2017).

Surgen otras publicaciones que, además de considerar el aborto como un tratamiento válido para los casos de infección congénita, van más allá al solicitar su liberación. Un ejemplo de esta postura está en Alvarado-Socarras y Rodriguez-Morales (2016), que afirman que es necesario alcanzar la evidencia de la asociación entre el ZIKV y los problemas congénitos para que se pueda discutir el acceso al aborto en estos casos -es decir, defienden que la evidencia de la asociación causal permitiría la realización el aborto como solución del problema y también permitiría la reivindicación del aborto en los lugares en donde este no es aprobado-. En la misma línea, la correspondencia de Mansuy et al. (2016) en Lancet infectious diseases, afirma que se deben buscar estrategias eficientes para un fácil acceso a medicamentos abortivos. Un pequeño editorial de Midwiferi, publicado por Simone Diniz, estaría también en esta vertiente de ofrecer el aborto como un tratamiento para los problemas relacionados con el ZIKV; sin embargo, lo propone abogando por el aborto como un derecho de la mujer. Se puede leer en el editorial:

\footnotetext{
Desafortunadamente en América Latina, donde la epidemia está golpeando con más fuerza, existe una legislación más restrictiva sobre el aborto, que agrega un ultraje a los daños, con el potencial de causar un daño aún mayor para la salud y el bienestar de las mujeres y aumentar la demanda de atención especial en los países donde esta atención está ausente o es muy limitada (Diniz 2016a ).
} 
Todavía en la misma argumentación, Cláudia Duarte dos Santos y Samuel Goldenberg (2016) publican un pequeño artículo sobre los desafíos del ZIKV y la microcefalia. El artículo, aun siendo breve, aporta un panorama general bastante consistente de la situación; sin embargo, en una determinada parte, el artículo sale de la temática del ZIKV y de los problemas congénitos para centrarse en la cuestión del aborto, afirmando -sin ningún dato científico que lo pueda fundamentar- que la prohibición del aborto en Brasil lleva a la práctica del aborto ilegal a gran escala y con gran riesgo para la vida de las madres.

Reforzando la misma postura, un comentario de Langer, Caglia y Menéndez (2016) en Sexual and Reproductive Health and Rights, aprovecha el ZIKV y la complejidad social de Latinoamérica y Caribe para abogar por el aborto. Utilizan números bastante elevados -como la afirmación de que en Latinoamérica y Caribe hubo, en 2008, 4,4 millones de abortos- sin presentar la fundamentación científica de estos datos ${ }^{6}$. Es verdad que, como se afirma en el artículo, el coste de la falta de conocimiento ha sido bastante elevado para la sociedad, para las mujeres y para los niños afectados; sin embargo, también es verdad que la aprobación del aborto no disminuiría esta carga (Derosa 2018, 377-379).

Con el avance de la crisis y de la polémica internacional surgen propuestas de profundizar en la discusión del aborto como un tratamiento aun cuando los casos concretos no se registran. Es el caso, por ejemplo, de un editorial de la revista Biomédica -revista oficial del Instituto Nacional de Salud de Colombia- firmado por Jaime Castellanos (2016). El editorial tiene como eje de su argumentación la incapacidad presentada por los países afectados de lograr el control del Aedes aegypti. Dentro de esta argumentación más amplia, el editorial afirma que cerca de 6.000 mujeres embarazadas estarían contaminadas por el ZIKV en Colombia, defendiendo la necesidad del debate

6 Un análisis profundo sobre la incoherencia entre las estimativas de abortos ilegales y los números reales de abortos en Brasil y otros países del mundo, además del número real de muertes maternas en consecuencia del aborto ilegal, se pueden ver en los capítulos 6 y 7 de Derosa, Marlon, edit. 2018. Precisamos falar sobre aborto: Mitos e verdades. Florianópolis: Estudos nacionais, pp. 209-266. 
sobre el aborto en casos de niños con malformaciones, pues las graves deficiencias neurológicas y cognitivas supondrían un peligro para la salud de la madre. En realidad, no existía -y todavía no existe- ningún tipo de evidencias, y ni siquiera indicios, de que la salud de la madre pudiera estar en riesgo como consecuencia del embarazo de niños con malformaciones por el ZIKV. Además, en el caso colombiano, pese a que existía de hecho un número significativo de notificaciones de mujeres embarazadas contaminadas por el ZIKV, en la época de la publicación del editorial no se había registrado ningún caso de niños con malformaciones causadas por el virus (Pacheco, et al. 2020).

A la vez, también surgen datos exagerados, valiéndose de las expectativas más pesimistas y de los números más elevados - sin comprobación científica- como intento de reforzar los problemas e insistir en el aborto como una de sus soluciones. Así se ve en dos breves comentarios de Lawrence Gostin y de James Hodge Jr. (2016 ${ }^{\mathrm{a}}$, 2016b), publicados en JAMA y en Lancet. En ambos textos se aboga, en primer lugar, por los recursos económicos que deberían ser destinados a la investigación del ZIKV; en segundo lugar, presentan números bastante elevados de mujeres infectadas que tendrían hijos con problemas congénitos; y, por último, explicitan -exigiendo la despenalización- la falta del acceso al aborto como un problema para las mujeres en los países afectados, y una falta de atención y de cuidado debidos en la epidemia.

También surgen defensas claras del aborto eugenésico como si fuera una especie de tratamiento. Es el caso, por ejemplo, del artículo de Lisa Goldthwaite y de Griselda Velásquez (2016), publicado incluso después del fin de la ESPII. ${ }^{7}$ Afirma que una de las causas para que el aborto pueda ser permitido en casos de infección por el ZIKV sería porque, en el caso de embarazos de mujeres infectadas, los fetos podrían ser afectados y, además, la inseguridad de estos embarazos -inseguridad generada, según

World Health Organization. 'Quinta reunión del Comité de Emergencia establecido en virtud del Reglamento Sanitario Internacional (2005) sobre la microcefalia, otros trastornos neurológicos y el virus de Zika'. 2016; Nov 18. http://www.who.int/mediacentre/ news/statements/2016/zika-fifth-ec/es/ [consultado el 13 de abril de 2020]. 
los artículos, por la posibilidad de infección de los niños- podría generar traumas emocionales a las madres. En este mismo artículo también se cita el aumento del aborto ilegal -como si ello pudiera justificar la aprobación del crimen de aborto-.

Podemos concluir este apartado con una breve mención al artículo de Thana Cristina de Campos, que, aunque apruebe el aborto, presenta ser un error considerarlo como una solución o un tratamiento para la epidemia: El aborto no es una solución efectiva para el brote de Zika, porque no aborda las causas del brote ni previene una mayor propagación de la infección. No añade nada en el control del vector o en las mejoras del saneamiento o en las medidas de precaución apropiadas (de Campos 2017).

\section{Argumentos que utilizan la problemática relacionada al ZIKV para proponer el aborto como un derecho fundamental de la mujer}

De modo distinto al apartado anterior, en este apartado, la línea argumentativa de las publicaciones que serán presentadas no defiende el aborto como un tratamiento válido, sino que directamente intentan aprovecharse de las circunstancias de la epidemia del ZIKV para defender el aborto como un derecho.

Una de las primeras y más fuertes publicaciones en este sentido es un pequeño artículo de Laura Rodrigues (2016). El título del artículo es bastante significativo, siendo ya un anuncio de su contenido: Zika: the tragedy and the opportunities. El artículo afirma: Incluso las peores tragedias pueden traer pequeñas oportunidades. Tal vez dos de los legados de esta ESPII sean un mejor reconocimiento de la necesidad de apoyo para niños discapacitados y la reapertura del debate sobre un derecho legal para que las mujeres elijan el curso de su embarazo en América Latina.

En el mismo fascículo de la revista se publica un artículo con un panorama general de la situación del ZIKV en Brasil. El artículo de Teixeira et al. (2016) -y que tiene a Laura Rodrigues, mencionada antes, como una de las coautoras- presenta, en su mayor parte, un carácter más científico. Sin 
embargo, en uno de los párrafos del artículo huye de la discusión propia sobre el ZIKV para abogar por el aborto como un derecho. Afirma que la situación pide la reapertura del debate sobre la interrupción del embarazo, pues sería necesario que la mujer pudiera elegir sobre la continuidad o interrupción de su embarazo y contar con un cuidado médico adecuado y con protecciones legales.

Siguiendo todavía en esta vertiente argumentativa, el comentario de Theall et al. (2017), publicado cuando ya había un conocimiento más profundo de la infección e incluso cuando ya había dejado de ser considerado una ESPII, titula uno de los apartados como la oportunidad zika. En este apartado, considerando el aborto entre los derechos reproductivos, señala: [...] el brote del virus del Zika -declarado una ESPII- no tiene por qué ser una crisis. Presenta una oportunidad sin precedentes para cambiar las políticas de salud pública, la legislación, el refuerzo y respaldo de los derechos de todas las mujeres a alcanzar el nivel más alto posible de salud y bienestar ahora y para el futuro.

La misma línea argumentativa se encuentra en un artículo de Marília Tavares y de Angel Foster (2016). La argumentación no propone siquiera el aborto como una solución para el problema, sino que se utiliza el problema del ZIKV para proponer la apertura del diálogo sobre el aborto. Afirman:

La crisis del ZIKV ha puesto de relieve el estado legal del aborto en gran parte de América Latina, incluido Brasil. Esta ESPII puede ofrecer una oportunidad para que activistas, médicos y especialistas en salud pública se movilicen para la contracepción basada en evidencias y para las políticas de aborto que ofrezcan a todas las mujeres, no sólo a aquellas que han estado expuestas al ZIKV, una mayor autonomía reproductiva.

Quizá el artículo que promueve más explícitamente la estrategia de aprovecharse de la problemática asociada a la epidemia por el ZIKV sea el de Brosco y Brosco (2016). La argumentación establece un paralelo entre la lucha por la legalización del aborto en Estados Unidos, a mediados del siglo $\mathrm{XX}$, y la lucha por la liberación del aborto en los países afectados por el ZIKV. Según los autores, en los años 40 y 50, las personas que buscaban el 
aborto en Estados Unidos eran consideradas por la opinión pública como personas sexualmente desviadas, racialmente inferiores o psicológicamente enfermas. La infección y los problemas congénitos asociados a la rubeola han sido el catalizador del cambio social en las políticas proaborto. Del mismo modo, ahora sería la oportunidad de utilizar la epidemia del ZIKV y los problemas congénitos asociados a esta infección, para convencer a la opinión pública de los países afectados por el ZIKV de que el aborto debería ser despenalizado.

El Caderno de saúde pública publica un artículo de Débora Diniz (2016b) - una de las principales figuras que reivindica el aborto en Brasil- titulado Virus Zika e mulheres. El artículo, más que aportar datos científicos, establece un relato claro de la situación de abandono vivida por las mujeres y las familias afectadas por el síndrome del zika congénito. La dificultad de renta y de políticas públicas en el noreste de Brasil -región más afectada por el ZIKV y los problemas congénitos asociados a la infección- es bastante bien descrito en el artículo. Sin embargo, la conclusión a la que llega no es la de exigir que estas mujeres y niños sean bien atendidos en sus derechos, sino reclamar que las mujeres afectadas por el ZIKV tengan derecho al aborto. Pocos meses más tarde, la misma autora publica un libro titulado Zika: do sertão nordestino à ameaça global (Diniz 2016c), con un contenido muy parecido al artículo anterior.

En un editorial de Lancet Global Health (2016) firmado por la propia revista, después de centrar la discusión en la polémica sobre el ZIKV y las Olimpiadas, y de afirmar que el ZIKV y los problemas congénitos afectarían de modo especial a las regiones más empobrecidas del país, aboga por el derecho al aborto como un derecho fundamental que estaría siendo negado a las mujeres embarazadas y con la posibilidad de tener niños afectados por el síndrome del zika congénito. El editorial alaba, en este sentido, las iniciativas de grupos y organizaciones internacionales que intentan forzar la aprobación del aborto en Brasil y en Latinoamérica.

Nuevamente Débora Diniz (2016d) publica, en agosto de 2016, un editorial en la revista Bioethics. Se trata de una argumentación breve y bastante objetiva, que se puede situar entre la defensa genérica del aborto como un 
derecho de la mujer y la preparación de la utilización de la problemática del ZIKV y los problemas congénitos como vía de conseguir un paso en dirección a la obtención del aborto como un derecho. Son tres los puntos de argumentación, siendo ellos presentados por el editorial como falacias éticas de la respuesta internacional a la crisis.

La primera de las falacias, según el artículo, sería la afirmación que hace la comunidad científica internacional de que necesitaríamos una certeza biomédica de la causalidad del ZIKV antes de tomar las medidas de atención a las mujeres y a los niños afectados, incluyendo la posibilidad de que las mujeres eligieran el aborto. La segunda falacia, según Diniz, ha sido medir el alcance de la epidemia por el número de niños con trastornos neurológicos relacionados con el ZIKV, marginando así a las mujeres afectadas, que ahora son las principales responsables de estos niños. La consecuencia es, según el artículo, que ha aumentado el número de abortos ilegales y las implicaciones del aborto inseguro para las mujeres. El editorial no fundamenta esta información con datos científicos o evidencias numéricas. La tercera falacia sería la afirmación de que existe un conflicto de interés entre los derechos reproductivos de las mujeres y los derechos de los discapacitados, siendo que, según el artículo, la defensa del aborto sería acusada injustamente de práctica eugenésica. Según Diniz, esto no sería un conflicto real, pues aquí se defiende el aborto como un derecho libre de la mujer por el miedo o por lo que llama "tortura" psicológica, y no como una afrenta a los discapacitados.

Todavía en abril de 2016 el instituto Anis, dirigido por Débora Diniz, publica un documental bastante sensible sobre la realidad del ZIKV y los problemas relacionados, con el foco centrado en las madres ${ }^{8}$. Pocos días después de la publicación del documental, Beatriz Galli (2016) publica el artículo ¿Dónde está el derecho al aborto? Comentario sobre el documental 'Zika, the film'. Lo que el artículo hace, en definitiva, es mezclar dos problemas completamente distintos, como si fueran un único problema o como si uno fuera consecuencia directa del otro: existe sí un problema real de abandono o al menos de falta de cuidado con muchas de las madres

8 Vozes da igualdade - o canal da Anis. 'Zika, the film'. 2016; Abr 17. https://www.youtube. com/watch?v=j9tqt0jaoG0 [consultado el 13 de abril de 2020]. 
y niños afectados; sin embargo, el aborto es un problema completamente distinto, siendo que, incluso de forma meramente lógica, la despenalización o legalización del aborto no es la solución para los problemas presentados.

Una reflexión bioética del tema es elaborada por Bueno y Grunspun (2016). El artículo afirma que, por el principio de autonomía, debería ser respetado simplemente la decisión y los valores propios de la madre, considerando la cuestión del aborto desde una perspectiva de creencias que deberían ser respetadas. El problema aquí es que no considera la cuestión social, el bien común y la vida del niño, además de los daños directos que el aborto produce en la propia mujer. El artículo concluye que la decisión del aborto no se debería basar exclusivamente en la decisión de la mujer, sino que debería ser parte absoluta de la confidencialidad profesional entre médico y paciente, es decir, en clara oposición a la legislación brasileña, en donde el aborto es un crimen.

En la misma dirección, Hodge et al. (2016) presentan, como señales de retraso cultural y social, el hecho de que el $80 \%$ de los brasileños sean contrarios al aborto, y afirma que la crisis por el ZIKV sería la ocasión propicia para alcanzar el derecho a la interrupción voluntaria del embarazo. Afirman, además, que sería necesario no solo el aborto en casos comprobados de ZIKV congénito, sino el aborto libre, pues algunos de los problemas congénitos por el ZIKV tendrían el diagnóstico apenas en la vigésimo segunda o vigésimo cuarta semana del embarazo -la limitación del aborto impediría, según el artículo, que estos embarazos pudieran ser interrumpidos-.

Se ha visto en el apartado anterior que, con el pasar de los meses, se empezaron a utilizar datos exagerados o expectativas pesimistas de tasas de infectadas por el virus que tendrían niños afectados por el síndrome del zika congénito para poder seguir abogando por el aborto como un tratamiento. Aquí se utiliza la misma estrategia. Con el pasar de los meses y la mejor comprensión de la epidemia y de los problemas asociados, empiezan a emplear datos que científicamente ya no correspondían a los temores de las hipótesis presentadas en el inicio de la epidemia. También se utilizan datos publicados, pero nunca comprobados, sobre el aborto de modo general, exagerando los números de abortos y de problemas relativos al llamado 
aborto inseguro. Esta estrategia es frecuentemente utilizada en la defensa del aborto, con el objetivo de convertirlo, sin evidencias científicas, en un problema de salud pública (Derosa 2018, 209-266). Así lo hace, por ejemplo, Hodge et al. (2016) con afirmaciones de que el 10\% de todas las muertes maternas de Latinoamérica y Caribe estarían causadas por el llamado aborto inseguro -dato presentado sin base empírica real y sin evidencias científicas claras-.

\section{Consecuencias de las argumentaciones previas: construcción de una narrativa social, política y jurídica que justificaría el aborto}

En enero de 2016, algunos días antes de que la OMS declarase que la epidemia por el ZIKV y los problemas relacionados a ella serían considerados una ESPII, se publica en Brasil una entrevista a Débora Diniz (Senra 2016). El instituto Anis, dirigido por ella y ya mencionado anteriormente, es una de las principales referencias brasileñas del lobby proaborto -ha conseguido, por ejemplo, que la Suprema Corte de Brasil aprobase el aborto en casos de anencefalia (meroanencefalia) ${ }^{9}$. Es evidente que, en el momento de la entrevista, los conocimientos científicos sobre el ZIKV y las consecuencias relacionadas con la infección en mujeres embarazadas eran muy reducidos -la confirmación de la asociación causal se alcanza en abril-. Aun así, en la entrevista concedida a la BBC Brasil, la activista afirma que pondría una demanda en la Suprema Corte de Brasil para exigir el derecho de aborto en casos de microcefalia relacionada al ZIKV. La argumentación jurídica utilizada, según la entrevista, se basaría en que el Estado había sido incompetente en el control del mosquito Aedes aegypti, y que las mujeres afectadas y con niños con malformaciones no podrían ser penalizadas por las consecuencias de políticas públicas ineficaces. La consecuencia, según

9 Supremo Tribunal Federal. Argüição de Descumprimento de Preceito Fundamental 54, ADPF 54. Plenário. Relator ministro Marco Aurélio. Julgamento em 12 de abril de 2012. Publicação em 30 de abril de 2013. http://www.stf.jus.br/portal/processo/verProcessoAndamento.asp?incidente=2226954 [consultado el 13 de abril de 2020]. 
la antropóloga, sería que las mujeres afectadas deberían tener el derecho de elegir el aborto legal. Débora Diniz sigue la argumentación afirmando:

Somos una organización que ya hizo esto antes. Y que lo ha logrado. Estamos plenamente inspiradas a repetirlo, sabiendo que vamos a enfrentar todas las dificultades judiciales y burocráticas que enfrentamos en la primera vez. [...] En 2004 no había una epidemia ni un vector (como el mosquito Aedes aegypti). Ahora ambos existen y esto exige una toma de providencias más urgente. [...] De otra parte, en la anencefalia los niños no nacían vivos y así podíamos huir de un debate moral. Pero ahora, sabemos que la microcefalia típica es un mal incurable, irreversible, sin embargo, el niño sobrevive (en la mayor parte de los casos). Por lo tanto, se trata del aborto de hecho y esto enfrenta resistencia.

En abril de 2016, un artículo publicado por Beatriz Galli y Suely Deslandes (2016) utiliza también la cuestión del ZIKV para defender la liberación del aborto en el ámbito político y jurídico. En pocas líneas, presentan un breve panorama sobre la cuestión del ZIKV en Brasil y en otros países de Latinoamérica, para después entrar en el centro de la temática del artículo: la cuestión político-jurídica del aborto. El artículo presenta como una conquista el hecho de que, en los casos de aborto despenalizados por ley en Brasil, la objeción de conciencia sólo pueda ser alegada cuando haya otro profesional que ejecute el aborto. Después afirma que hay una formación conservadora de raíz religiosa en el Congreso Nacional brasileño, que sería, según el artículo, contraria a la laicidad del Estado y que, bajo el argumento de la "defensa de la vida", representa una amenaza a lo que las autoras consideran derechos ya conquistados.

Otro artículo publicado en la misma revista -Cadernos de saúde públi$c a-$ por Thais Medina Camargo (2016), establece un paralelismo entre la discusión político-jurídica brasileña de intento de aprobación del aborto en contaminadas por el HIV y la situación actual de intento de aprobación del aborto por el ZIKV. Según la autora, la situación política y social era mucho más favorable para la aprobación del aborto en los años 90. También refuerza -con datos históricos- que la estrategia para la aprobación debería ser siempre el llamado litigio estratégico, es decir, por la vía jurídica antes 
que por la vía legislativa. La conclusión del artículo es una clara defensa del derecho a que las mujeres puedan decidir abortar, aunque para esto deben conseguir no sólo la judicialización de las decisiones, sino también el apoyo de la opinión pública.

Se sabe que a finales de agosto de 2016 la situación y preocupación sobre el ZIKV y los problemas congénitos ya había perdido la fuerza inicial. La gran concentración de los casos en una única región de Brasil, el fin de las Olimpiadas -cumpliendo las proyecciones más optimistas con relación al ZIKV durante los Juegos-, la más baja incidencia de la enfermedad y la sospecha de la necesidad de cofactores para el desarrollo de problemas congénitos asociados al ZIKV, había llevado a esta pérdida de importancia a finales de 2016 y primeros meses de 2017. Sin embargo, es justamente en este periodo, a finales de agosto de 2016, cuando se solicita, a la Suprema Corte brasileña, la despenalización del aborto en casos de contaminación de la madre por el ZIKV. La petición completa, con casi cien páginas, ha sido presentada por la Associação Nacional dos Defensores Públicos y pasa a ser registrada en la Suprema Corte como acción directa de inconstitucionalidad 5.581 (ADI 5.581). ${ }^{10} \mathrm{El}$ instituto de bioética Anis, que inicialmente afirmó que sería el autor de la acción, entra como un colaborador de la petición, bajo la figura jurídica conocida como amicus curiae. ${ }^{11}$

El contexto -final de los Juegos Olímpicos de Río de Janeiro y caída masiva en el número de casos de afectaciones congénitas por el ZIKV-, contradice el tono de la petición y de la repercusión asociada. Un día después de la presentación de la ADI 5.581, el BMJ publica una noticia sobre la petición. En la noticia, firmada por Claudia Collucci (2016), se deja evidencia de que la población brasileña es contraria al aborto, incluso en casos de ZIKV, y presenta como si fuera un problema el hecho de que el aborto sea un crimen en la mayoría de los países de Latinoamérica.

10 Supremo Tribunal Federal. Ação direta de inconstitucionalidade - ADI/5.581. Petição inicial (46472/2016). http://redir.stf.jus.br/estfvisualizadorpub/jsp/consultarprocessoeletronico/ ConsultarProcessoEletronico.jsf?seqobjetoincidente=5037704 [consultado el 13 de abril de 2020].

11 Supremo Tribunal Federal. Ação direta de inconstitucionalidade - ADI/5.581. Pedido de ingresso como amicus curiae (61697/2016). http://redir.stf.jus.br/paginadorpub/paginador. jsp?docTP=TP \&docID=598586279\&prcID=5037704\# [consultado el 13 de abril de 2020]. 


\section{Conclusiones}

A partir de la exposición realizada en los apartados anteriores, es posible ver que el ZIKV, la epidemia causada por este virus (principalmente en Brasil) y el llamado síndrome del zika congénito, fueron problemas graves, que debido a la falta de conocimiento han originado grandes preocupaciones y efectos graves principalmente en la región noreste de Brasil. Pasado el brote epidémico y sin que se concretizasen las previsiones pandémicas iniciales, todas estas preocupaciones pasaron a un segundo plano. Se puede decir incluso que el síndrome del ZIKV congénito se ha convertido en una enfermedad olvidada.

A la vez, se puede ver que, de modo paralelo a la crisis real manifestada por la enfermedad y los problemas congénitos, algunos autores del ámbito científico biomédico y algunos activistas del lobby proaborto utilizaron la crisis para incluir la defensa del aborto -considerando el acceso legal al aborto como parte integrante de la problemática relacionada al virus-. También es verdad que no todos estos personajes actuaron del mismo modo.

Es necesario ver que aquellos que proponen el aborto como una forma más de tratamiento para el llamado síndrome del zika congénito se equivocan desde el punto de vista científico, pues las premisas de las que parten no son coherentes con los hechos biológicos empíricamente observables o, dicho en otros términos, no hay ninguna evidencia científica que pueda justificar el aborto como un tratamiento específico para la madre o para los niños afectados por el ZIKV (Derosa 2018, 365-382). Siendo así, en el contexto presentado, la defensa del aborto parte de una incomprensión de los hechos científicos o de una defensa ideológica desconectada de ellos.

Además de un equívoco científico, tanto estos autores como los que defendieron el aborto como un derecho de la mujer en medio de esta crisis sanitaria de Brasil, promovieron también acciones contrarias a la justicia al intentar destinar los recursos que ya eran escasos a la práctica del aborto, que no era un medio eficaz para el control de la enfermedad y sus consecuencias. ${ }^{12}$

12 Para una profundización teológica del tema, ver la unidad entre la dignidad humana, el principio de subsidiariedad y el principio de solidaridad en Gregorio Guitián, "El principio de solidaridad de la Doctrina Social de la Iglesia: fundamentación teológica," Scripta theologica 52(2020)3: 553-585. 
En este sentido, retomamos aquí el importante artículo publicado por Thana Cristina de Campos (2016) -ya citado anteriormente-, que ilustra la estrategia -y el error de ésta- promovida para utilizar la epidemia del ZIKV y los problemas asociados a la infección como un mecanismo para aprobar el aborto en Brasil y demás países de Latinoamérica. La autora -aun defendiendo que el aborto debería ser un derecho de las mujeres- afirma:

El aborto no es una solución efectiva para el brote de Zika, porque no aborda las causas del brote ni previene una mayor propagación de la infección. No hace nada para controlar el vector o para mejorar el saneamiento y las medidas de precaución apropiadas. [...] En resumen, la epidemia de Zika no es el lugar para tener este debate, porque las controversias morales del aborto distraen a la ley y a los legisladores de lo que se necesita hacer para abordar el brote de manera efectiva. Las prioridades en la asignación de recursos de atención a la salud deben establecerse con cuidado, dado que los recursos son escasos. [...] Para abordar el brote de Zika con éxito, por lo tanto, Brasil -y particularmente la frágil administración Rousseff / Temer- necesita enfocar sus energías en cuestiones específicas de salud en lugar de hacerlo en las intratables cuestiones morales.

Por fin, podemos concluir, con base en los datos científicos, que no existe una contradicción entre el absoluto moral que prohíbe el aborto y los datos científicos presentados en la investigación sobre el ZIKV. De este modo, la inmoralidad del aborto no se da a partir de una norma desconectada de la realidad, sino que la norma deriva de la realidad misma de los hechos. Promover el aborto a partir de una crisis sanitaria no solo promueve las injusticias vistas anteriormente, sino que incluso son contrarias a los propios hechos científicos.

\section{Bibliografía}

Alvarado-Socarras, Jorge Luis, and Alfonso Javier Rodriguez-Morales. 2016. "Etiological agents of microcephaly: implications for diagnosis during the current Zika virus epidemic.” Ultrasound Obstet Gynecol 47(4): 525-526.

Brito, Milena Bastos, and Ian S. Fraser. 2016. "Zika virus outbreak and the poor brazilian family planning program.” Rev Bras Ginecol Obstet 38(12): 583-584. 
Brosco, Joia Hordatt, and Jeffrey P. Brosco. 2016. “Zika as a catalyst for social change.” Pediatrics 138(6): e20162095.

Bueno, Marco Aurélio, and Henrique Grunspun. 2016. "Bioethical considerations at times of Zika virus.” Einstein (Sao Paulo) 14(2): 13-18.

Camargo, Thais Medina. 2016. "The debate on abortion and Zika: lessons from the AIDS epidemic.” Cad Saude Publica 32(5): e00071516.

Campos, Gubio S., Antonio C. Bandeira, and Sílvia I. Sardi. 2015. "Zika virus outbreak, Bahia, Brazil.” Emerg Infect Dis. 21(10): 1885-1886.

Castellanos, Jaime E. 2016. “Zika: a defeat in the struggle against Aedes aegypti.” Biomedica 36(1): 5-9.

Collucci, Claudia. 2016. "Brazilian attorneys demand abortion rights for women infected with Zika.” BMJ. 354: i4657.

de Campos, Thana Cristina. 2017. "Zika, public health, and the distraction of abortion.” Med Health Care Philos. 20(3): 443-446.

Derosa, Marlon, edit. 2018. Precisamos falar sobre aborto: Mitos e verdades. Florianópolis: Estudos nacionais.

Dick, George W., Stuart F. Kitchen, and Alexander John Haddow. 1952. “Zika virus I. Isolations and serological specificity.” Trans R Soc Trop Med Hyg. 46(5): 509-520.

Dick, Geroge W. 1952. “Zika virus II. Pathogenicity and physical properties.” Trans $R$ Soc Trop Med Hyg. 46(5): 521-534.

Diniz, Débora. 2016b. “Zika virus and women.” Cad Saude Publica 32(5): e00046316.

Diniz, Débora. 2016c. Zika: do sertão nordestino à ameaça global. Rio de Janeiro: Civilização brasileira.

Diniz, Débora. 2016d. “Zika virus, women and ethics.” Dev World Bioeth. 16(2): 62-63.

Diniz, Simone Grilo. 2016a. "Zika virus and pregnancy: A perspective from Brazil.” Midwifery 35: 22-23.

Duarte dos Santos, Claudia Nunes, and Samuel Goldenberg. 2016. “Zika virus and microcephaly: challenges for a long-term agenda.” Trends Parasitol. 32(7): 508-511.

Galli, Beatriz, and Suely Deslandes. 2016. "Threats of retrocession in sexual and reproductive health policies in Brazil during the Zika epidemic.” Cad Saude Publica 32(4): e00031116.

Galli, Beatriz. 2016. "Where is the right to abortion? Comment on the documentary Zika, the film.” Cad Saude Publica 32(6): eES010616.

Goldthwaite, Lisa M., and Griselda Velasquez. 2016. "Family planning and the Zika era." Curr Opin Obstet Gynecol. 28(6): 499-503.

Gostin, Lawrence Oglethorpe, and James G. Hodge Jr. 2016a. “Is the United States prepared for a major Zika virus outbreak?” JAMA 315(22): 2395-2396. 
Gostin, Lawrence Oglethorpe, and James G. Hodge Jr. 2016b. “Zika virus and global health security.” Lancet Infect Dis. 16(10): 1099-1100.

Guitián, Gregorio. 2020. "El principio de solidaridad de la Doctrina Social de la Iglesia: fundamentación teológica.” Scripta theologica 52(3): 553-585.

Hajra, Adrija, Dhrubajyoti Bandyopadhyay, Lyndsey R Heise, Rajarshi Bhadra, Somedeb Ball, and Shyamal Kumar Hajra. 2017. "Zika and pregnancy: A comprehensive review." Am J Reprod Immunol. 77(2): 1-7.

Hayes, Edward B. 2009. “Zika virus outside Africa.” Emerg Infect Dis. 15(9): 1347-1350.

Hodge, James G., Alicia Corbett, Ashley Repka, and P. J. Judd. 2016. “Zika virus and global implications for reproductive health reforms." Disaster Med Public Health Prep. 10(5): 713-715.

Juan Pablo II. Encíclica Evangelium Vitae, 25 de marzo de 1995.

Kucharski, Adam J., Sebastian Funk, Rosalind M. Eggo, Henri-Pierre Mallet, William John Edmunds, and Eric J Nilles. 2016. “Transmission dynamics of Zika virus in island populations: a modelling analysis of the 2013-14 French Polynesia outbreak." PLoS Negl Trop Dis. 10(5): e0004726.

Lancet Global Health. 2016. The right(s) approach to Zika. Lancet Glob Health. 4(7), e427.

Langer, Ana, Jacquelyn M. Caglia, and Clara Menéndez. 2016. "Sexual and reproductive health and rights in the time of Zika in Latin America and the Caribbean." Stud Fam Plann. 47(2): 179-181.

Mansuy, Jean Michel, Marine Dutertre, Catherine Mengelle, Camille Fourcade, Bruno Marchou, Pierre Delobel, Jacques Izopet, and Guillaume Martin-Blondel. 2016. "Zika virus: high infectious viral load in semen, a new sexually transmitted pathogen?” Lancet Infect Dis. 16(4): 405.

Pacheco, Oscar, Mauricio Beltrán, Christina A. Nelson, Diana Valencia, Natalia Tolosa, Sherry L. Farr, Ana V. Padilla, Van T. Tong, Esther L. Cuevas, Andrés Espinosa-Bode, Lissethe Pardo, Angélica Rico, Jennita Reefhuis, Maritza González, Marcela Mercado, Pablo Chaparro, Mancel Martínez Duran, Carol Y. Rao, María M. Muñoz, Ann M. Powers, Claudia Cuéllar, Rita Helfand, Claudia Huguett, Denise J. Jamieson, Margaret A. Honein, and Martha L. Ospina Martínez. 2020. “Zika virus disease in Colombia - preliminary report.” N Engl J Med. 383(6): e44. Rasanathan, Jennifer J. K., Sarah MacCarthy, Debora Diniz, Els Torreele, and Sofia Gruskin. 2017. "Engaging human rights in the response to the evolving Zika virus epidemic.” Am J Public Health 107(4): 525-531.

Rodrigues, Laura C. 2016. "Zika: The Tragedy and the Opportunities.” Am J Public Health 106(4): 582. 
Senra Ricardo. 2016. "Grupo prepara ação no STF por aborto em casos de microcefalia.” BBC Brasil. Enero, 28. Consultado el 13 de abril de 2020. http://www.bbc. com/portuguese/noticias/2016/01/160126_zika_stf_pai_rs.

Simpson, David I. 1964. “Zika virus infection in man.” Trans R Soc Trop Med Hyg. 58: 335-338.

Tavares, Marília P., Angel M. Foster. 2016. "Emergency contraception in a public health emergency: exploring pharmacy availability in Brazil." Contraception 94(2): 109-114.

Teixeira, Maria G., Maria da Conceição N. Costa, Wanderson K. de Oliveira, Marilia Lavocat Nunes, and Laura C. Rodrigues. 2016. "The epidemic of Zika virus-related microcephaly in Brazil: detection, control, etiology, and future scenarios." Am J Public Health 106(4): 601-605.

Theall, Katherine P., Maeve Wallace, and Dawn M. Wesson. 2017. "Zika: a missed opportunity to protect women's health and prevent unwanted pregnancies." Womens Health Issues 27(1): 2-4. 